\title{
Phase II study of sequential hormonal therapy with anastrozole/ exemestane in advanced and metastatic breast cancer
}

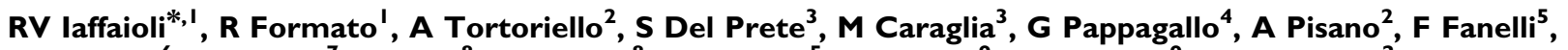 \\ G lanniello ${ }^{6}$, S Cigolari ${ }^{7}$, C Pizza ${ }^{8}$, O Marano ${ }^{8}$, G Pezzella ${ }^{5}$, T Pedicini', A Febbraro ${ }^{9}$, P Incoronato ${ }^{2}$, L Manzione ${ }^{10}$, \\ E Ferrari', N Marzano' ', S Quattrin' ${ }^{2}$, S Pisconti ${ }^{5}$, G Nasti', G Giotta' ${ }^{12}$, G Colucci ${ }^{12}$ and other Goim authors \\ IINT G Pascale, Naples, Italy; ${ }^{2}$ Med Onc Pozzuoli, Naples, Italy; ${ }^{3}$ Frattamaggiore H, Naples, Italy; ${ }^{4}$ Department of Oncology, PF Calvi Hospital, Noale, \\ Venise, Italy; ${ }^{5}$ Med Onc Taranto H, Naples, Italy; ${ }^{6}$ Med Onc Benevento H, Naples, Italy; ${ }^{7}$ MED ONC SA H, Naples, Italy; ${ }^{8}$ Med Onc Nola, Naples, Italy; \\ ${ }^{9}$ Fatebenefratelli Benevento H, Naples, Italy; ${ }^{10}$ Med Onc Potenza H, Naples, Italy; "'ASL BA I, Naples, Italy; ${ }^{2}$ Med Onc INT Bari, Naples, Italy by the \\ Southern Italy Oncology Group (GOIM)
}

\begin{abstract}
Hormonal therapy is the preferred systemic treatment for recurrent or metastatic, post-menopausal hormone-receptor-positive breast cancer. Previous studies have shown that there is no cross-resistance between exemestane and reversible aromatase inhibitors. Exposure to hormonal therapy does not hamper later response to chemotherapy. Patients with locally advanced or metastatic, hormonal receptor positive or unknown, breast cancer were treated with oral anastrozole, until disease progression, followed by oral exemestane until new evidence of disease progression. The primary end point of the study was clinical benefit, defined as the sum of complete responses (CR), partial responses (PR) and $>24$ weeks stable disease (SD). In all, 100 patients were enrolled in the study. Anastrozole produced eight CR and 19 PR for an overall response rate of 27\% (95\% Cl: I8.6-36.8\%). An additional 46 patients had long-term (>24 weeks) SD for an overall clinical benefit of 73\% (95\% Cl: 63.2-8I.4). Median time to progression (TTP) was II months (95\% Cl: 10-12). A total of 50 patients were evaluated for the second-line treatment: exemestane produced one CR and three PR; 25 patients had SD which lasted $\geqslant 6$ months in 18 patients. Median TTP was 5 months. Toxicity of treatment was low. Our study confirms that treatment with sequential hormonal agents can extend the period of time during which endocrine therapy can be used, thereby deferring the decision to use chemotherapy.
\end{abstract}

British Journal of Cancer (2005) 92, I62I-1625. doi:I0.1038/sj.bjc.6602579 www.bjcancer.com

Published online 26 April 2005

(C) 2005 Cancer Research UK

Keywords: sequential hormonal therapy; breast cancer

Treatment of metastatic breast carcinoma is still controversial. The introduction of new cytotoxic drugs and new chemotherapic regimens has, up to now, not resulted in a significant increase in survival.

Endocrine therapy is the preferred systemic treatment for recurrent or metastatic hormone-receptor-positive post-menopausal breast cancer (Carlson and Henderson, 2003), since it is well known that breast cancers expressing the oestrogen receptor (ER) and/or progesterone receptor (PgR) are sensitive to an increasingly wide variety of hormonal therapies (Carlson, 2002). Many patients who have been treated with Tamoxifen (Tam), which is still the standard hormonal treatment for breast carcinoma in the adjuvant setting, need new drugs with antiproliferative effects on oestrogen-dependent breast tumours. The available therapies include Tamoxifen or ovarian ablation (surgical oophorectomy, radiotherapeutic ablation or pharmacologically induced) in pre-menopausal women, Tamoxifen or aromatase inhibitors (AIs) in post-menopausal women, and the progestins, androgens and high-dose oestrogens for both pre- and post-menopausal patients.

*Correspondence: Dr RV laffaioli, Tr Michele Pietravalle, 54 - 80I31 Naples, Italy; E-mail: eiaffaioli@hotmail.com; roberta.formato@tin.it Received 4 October 2004; revised 7 March 2005; accepted 7 March 2005; published online 26 April 2005
Importantly, exposure to endocrine treatment does not seem to hamper later response to chemotherapy (Taylor et al, 1986). Since the goal of treating metastatic breast cancer is palliative (Hortobagyi, 1998a), minimally toxic alternatives are needed to improve clinical symptoms, to maintain acceptable performance status and quality of life, and to delay the need for chemotherapy. As endocrine therapies have developed, it has become recognised that a response to one therapy is predictive of a response to further hormonal therapy (Buzdar and Hortobagyi, 1998; Hortobagyi, 1998b). The sequential use of endocrine therapy alone offers significant quality-of-life advantages over cytotoxic chemotherapy (Buzdar and Hortobagyi, 1998), since it offers disease control without the side effects associated with cytotoxic agents. The development of novel endocrine therapies may extend the period of time during which sequential endocrine therapy can be used, thereby postponing the need for cytotoxic chemotherapy. Traditionally, the sequence of endocrine therapies was determined by the relative toxicity of the respective agents, with the least toxic being used first. However, more recently, the relative efficacy of agents has become an increasingly important consideration, particularly since AIs have been shown to represent clinically relevant alternatives to Tamoxifen in women with hormone receptor-positive breast cancer (Carlson et al, 2003). 
Anastrozole (AN), the first third-generation nonsteroidal AI approved in the USA, acts by reversibly binding to the aromatase enzyme and shows a low toxic profile, because it does not inhibit the production of adrenal steroids, nor does it determine the occurrence of thrombotic events as frequently as with tamoxifen (Bonneterre et al, 1999). The rationale for the use of this drug as first-line therapy in postmenopausal patients is supported by European (Robertson et al, 1999) and American (Nabholtz et al, 2000) phase III studies $v$ s tamoxifen, which have demonstrated an equivalent efficacy, an increase in time to progression (TTP; 11.1 months for AN and 5.6 months for Tam) and a lower incidence of thrombotic events, indicating the possibility of considering AN as a first-line treatment for patients with advanced breast carcinoma. On the other hand, negative data have also been reported (Nabholtz et al, 2003).

Exemestane (Exe) is a second-generation, steroidal AI which irreversibly binds to the enzyme aromatase. The novel aromatase inactivator Exe has been evaluated extensively in phase I and II studies at dosages of up to $600 \mathrm{mg} \mathrm{day}^{-1}$. It is well tolerated and, as a consequence, a maximum-tolerated dose has not been identified (Di Salle et al, 1994; Johannessen et al, 1997). Oral Exe 10$25 \mathrm{mg} \mathrm{day}^{-1}$ suppresses plasma oestrogens to as much as $6-15 \%$ of pretreatment levels (Johannessen et al, 1997). In two phase II uncontrolled studies, objective response (OR) rates with Exe as second-line therapy in postmenopausal women with advanced breast cancer were 22 and $28 \%$, and overall success rates (defined as the proportion of patients with OR or stable disease (SD) for $\geqslant 24$ weeks; sometimes described by other authors as 'clinical benefit' (Buzdar et al, 1998; Dombernowsky et al, 1998) were 47 and 48\%, respectively (Jones et al, 1998; Kvinnsland et al, 1998).

Phase II studies suggest that there is no cross-resistance between Exe and reversible inhibitors of aromatase and that the tolerability profile is excellent. Therefore, a sequential approach with AN followed by exemestane is worth pursuing, even upon the availability of newer compounds such as fulvestrant and trilostane.

On the basis of these considerations, we performed a phase II study which evaluated the activity of AN, a type II AI, as a first-line drug, and, in the event of disease progression, of exemestane, type $\mathrm{I}$, in patients with metastatic breast carcinoma.

\section{MATERIALS AND METHODS}

\section{Patient selection}

This study was initiated in November 2000 and closed to accrual in November 2002, was conducted at 13 sites within the Gruppo Oncologico Italia Meridionale (GOIM - Southern Italy Oncology Group). All patients were required to have a cytological or histological confirmed diagnosis of locally advanced or metastatic or primary breast cancer, not susceptible to surgical or radiological treatment and measurable disease.

All patients were required to have an ECOG performance status (WHO scale) $\leqslant 2$, and to be postmenopausal or premenopausal in treatment with $\mathrm{LH}-\mathrm{RH}$ agonist. Postmenopausal women were defined as those $\geqslant 50$ years of age who had not menstruated during the preceding 12 months or who had castrate follicle-stimulating hormone levels $\left(>40 \mathrm{IUl}^{-1}\right.$ ), those younger than 50 years of age who had castrate follicle-stimulating hormone levels $\left(>40 \mathrm{IU} \mathrm{l}^{-1}\right)$ or those who had undergone a bilateral oophorectomy.

Prior adjuvant chemotherapy or hormonal therapy with Tamoxifen for early breast cancer was permitted, provided that the patient had not received tamoxifen in the 6 months prior to entry into the trial.

Patients were required to have tumours that were ER-positive and/or PgR-positive or were of unknown receptor status. Patients with negative receptors or with one negative and the other unknown were excluded from the study. Other exclusion criteria were patients with cerebral metastasis, diffuse bilateral lymphangitis or patients with only osteoblastic bone metastasis, or with both lytic and osteoblastic lesions in which fewer than $50 \%$ of the lesions were lytic, when there were not other measurable lesions.

Patients with more than one previous chemotherapeutic line for metastatic disease, prior therapy with AIs, uncontrolled cardiologic dysfunctions, a low compliance to treatment, and other concomitant or previous malignancies (except for basal cell carcinoma and carcinoma in situ of the cervix) were excluded, too. The study was approved by the Ethic Committees of the participating centres and all patients gave their informed written consent.

\section{Treatment plan}

Eligible patients were treated as follows: $\mathrm{AN}$, one $1 \mathrm{mg}$ tablet daily, until clear evidence of progression; exemestane, one $25 \mathrm{mg}$ tablet daily, from evidence of progression after AN therapy until further evidence of disease progression. Subsequent therapy was left up to the discretion of the investigator, and follow-up was performed until death.

\section{Patient evaluations}

Baseline screening assessments were completed 2 weeks before the treatment. These assessments included demographic information, a complete history and a clinical visit to document the sites of disease. Laboratory studies included chest X-ray, liver scan by ultrasound, computed tomography (CT) scan, or magnetic resonance imaging, bone scan, and bone survey or X-rays of areas that were found suggestive of abnormality on the bone scan. Blood samples were collected for haematology and blood chemistry (general and specific, tumour markers). A history of diseaserelated symptoms was also documented.

A clinical visit, general and specific (tumour markers) laboratory procedures, total-body CT scan were repeated at a 3-months interval; bone scans were repeated every 12 months.

Response to treatment was evaluated according to RECIST criteria. Time to progression was measured in all patients as the time (in months) from the start of study drug to the date of evidence of progressive disease or death (or last follow-up in absence of unfavourable event). Toxicity was evaluated according to CTC criteria (CTC version 2.0. Cancer Therapy Evaluation Program. Common Toxicity Criteria, Version 2.0. DCTD, NCI, NIH, DHHS. March 1998. Publish Date: April 1999).

Patients were withdrawn from active treatment if there was evidence of clinically significant breast cancer progression, or a serious adverse event. Patient noncompliance with protocol procedures, or unwillingness or inability to continue the trial was also a reason for patient removal from the trial.

\section{Statistical considerations}

The primary objective of the study was to evaluate the study drugs in terms of clinical benefit (complete response (CR) + partial response $(\mathrm{PR})+$ stabilisation of disease (SD) $>6$ months). Secondary objectives were major $(C R+P R)$ response rate, TTP and toxicity. The sample size calculation for both single-stage studies was performed as proposed by A'Hern (2001), this method being an exact version of the algorithm first presented by Felming (1982).

The AN evaluation required 93 subjects to decide whether the proportion of patients with a clinical benefit $(P)$ was $\leqslant 50 \%$ or $\geqslant 65 \%$. If the number of patients with clinical benefit was $\geqslant 55$, the hypothesis that $P \leqslant 50 \%$ was rejected with a target error rate of 0.050 and an actual error rate of 0.048 . If the number of patients with clinical benefit was $\leqslant 54$, the hypothesis that $P \geqslant 65 \%$ was 
rejected with a target error rate of 0.100 and an actual error rate of 0.099 .

The exemestane evaluation required 47 subjects to decide whether $P$ was $\leqslant 20 \%$ or $\geqslant 40 \%$. If the number of patients with clinical benefit was $\geqslant 15$, the hypothesis that $P \leqslant 20 \%$ was rejected with a target error rate of 0.050 and an actual error rate of 0.037 . If the number of patients with clinical benefit was $\leqslant 14$, the hypothesis that $P \geqslant 40 \%$ was rejected with a target error rate of 0.100 and an actual error rate of 0.099 .

\section{RESULTS}

\section{Patient population}

Between November 2000 and November 2002, 100 patients aged 30-93 years (median: 66) were enrolled in the study. The patient characteristics are presented in Table 1.

\section{First-line AN}

Eight CRs (8\%) and 19 PRs (19\%) were observed, providing an OR rate of $27 \%$ (95\% CI: $18.6-36.8 \%)$. In all, 46 additional patients had a long-term disease stabilisation (SD after $\geqslant 6$ months), providing a clinical benefit rate of $73 \%$ (95\% CI: $63.2-81.4)$; thus, $\mathrm{AN}$ was considered as active at the level of clinical interest as above

Table I Demographic characteristics

\begin{tabular}{|c|c|c|c|c|}
\hline \multirow[b]{2}{*}{$\begin{array}{l}\text { Characteristic ( } 100 \\
\text { patients) }\end{array}$} & \multirow[b]{2}{*}{$n$} & \multirow[b]{2}{*}{$\%$} & \multicolumn{2}{|c|}{$n=\%$} \\
\hline & & & $\begin{array}{r}\text { Pt } \\
\text { exemes }\end{array}$ & $\begin{array}{l}\text { vith } \\
\text { patients) }\end{array}$ \\
\hline \multicolumn{5}{|l|}{ Age (years) } \\
\hline Median & 66 & & & \\
\hline Range & $30-93$ & & & \\
\hline \multicolumn{5}{|l|}{ Prior adjuvant treatment } \\
\hline Hormonal only & 21 & 21 & & \\
\hline Cytotoxic only & 25 & 25 & & \\
\hline Both & 30 & 30 & & \\
\hline None & 15 & 15 & & \\
\hline Unknown & 9 & 9 & & \\
\hline \multicolumn{5}{|l|}{ Sites of metastatic disease } \\
\hline Bone & 52 & 52 & 30 & 60 \\
\hline Skin & || & | | & 6 & 12 \\
\hline Lymph & 16 & 16 & 9 & 18 \\
\hline Pleural effusion & 6 & 6 & 5 & 10 \\
\hline Liver & 19 & 19 & 15 & 30 \\
\hline Lung & 14 & 14 & 10 & 20 \\
\hline Breast & 17 & 17 & 10 & 20 \\
\hline \multicolumn{5}{|l|}{ Numbers of sites involved } \\
\hline I & 64 & 64 & 23 & 46 \\
\hline 2 & 26 & 26 & 15 & 30 \\
\hline 3 & 8 & 8 & 10 & 20 \\
\hline$>4$ & 2 & 2 & 2 & 4 \\
\hline \multicolumn{5}{|l|}{ Performance Status } \\
\hline 0 & 43 & 43 & 21 & 42 \\
\hline I & 40 & 40 & 19 & 38 \\
\hline 2 & 17 & 17 & 10 & 20 \\
\hline \multicolumn{5}{|l|}{ Receptor status } \\
\hline $\mathrm{ER}+, \mathrm{PgR}+$ & 66 & 67 & & \\
\hline $\mathrm{ER}+, \mathrm{PgR}-$ & 8 & 8 & & \\
\hline ER+, PgR unknown & 0 & 0 & & \\
\hline ER-, PgR+ & 5 & 5 & & \\
\hline ER unknown, PgR+ & 0 & 0 & & \\
\hline Unknown & 19 & 19 & & \\
\hline
\end{tabular}

defined. Five other patients had a stabilisation lasting 4-6 months, and 19 had a PD (see Table 2). Three patients were not evaluable for response: one had a severe osteo-arthromyalgia, and two left the study by their own choice (in the absence of PD or any evident adverse reaction).

In all, 84 patients discontinued the first-line AN therapy, three before evaluation of activity (see above) and 81 because of a PD. The median duration of AN therapy was 9 months (range: 3-30+ months), for a median follow-up of 15 months (range: 3-32+ months). The median Kaplan-Meier progression-free survival estimate was 11 (95\% CI: $10-12)$ months (Figure 1).

First-line AN was well tolerated. No patient manifested any thrombo-embolic event or bone fracture. Seven $(7 \%)$ patients had a grade 1-2 osteo-articular pain, 20 (20\%) manifested hot flushes and 19 (19\%) manifested a grade 1-2 nausea and vomiting.

\section{Second-line exemestane}

Five of 13 treatment centres did not agree to participate in the activity trial of exemestane in patients progressing after first-line $\mathrm{AN}$; thus, 50 patients were eligible for this study. One CR (2\%) and three PR (6\%) were observed in patients treated with exemestane, for an overall response rate of $8 \%$ (95\% CI: $2.2-19.2 \%$ ) (see Table 2). The patient who achieved a CR had had a CR also following first-line AN therapy; on the other hand, all of the three patients who achieved a PR following exemestane had progressed while on previous AN therapy.

Table 2 Objective tumour response rates

\begin{tabular}{lcc}
\hline Response & $\begin{array}{c}\text { Anastrazole } \\
\mathbf{I ~} \mathbf{~ m g}\end{array}$ & $\begin{array}{c}\text { Exemestane } \\
\mathbf{2 5} \mathbf{~ m g}\end{array}$ \\
\hline CR & $\mathbf{I 0 0} \mathbf{( \% )}$ & $\mathbf{n = 5 0 ~ ( \% )}$ \\
PR & $8(8 \%)$ & $1(2 \%)$ \\
Objective response rate & $19(19 \%)$ & $3(6 \%)$ \\
SD $\geqslant 24$ weeks & $27(27 \%)$ & $4(8 \%)$ \\
Clinical benefit (CR+PR+SD $\geqslant 24$ & $46(46 \%)$ & $18(36 \%)$ \\
weeks) & $73(73 \%)$ & $22(44 \%)$ \\
SD $<24$ weeks & $5(5 \%)$ & $7(14 \%)$ \\
Progression & $19(19 \%)$ & $20(40 \%)$ \\
\hline
\end{tabular}

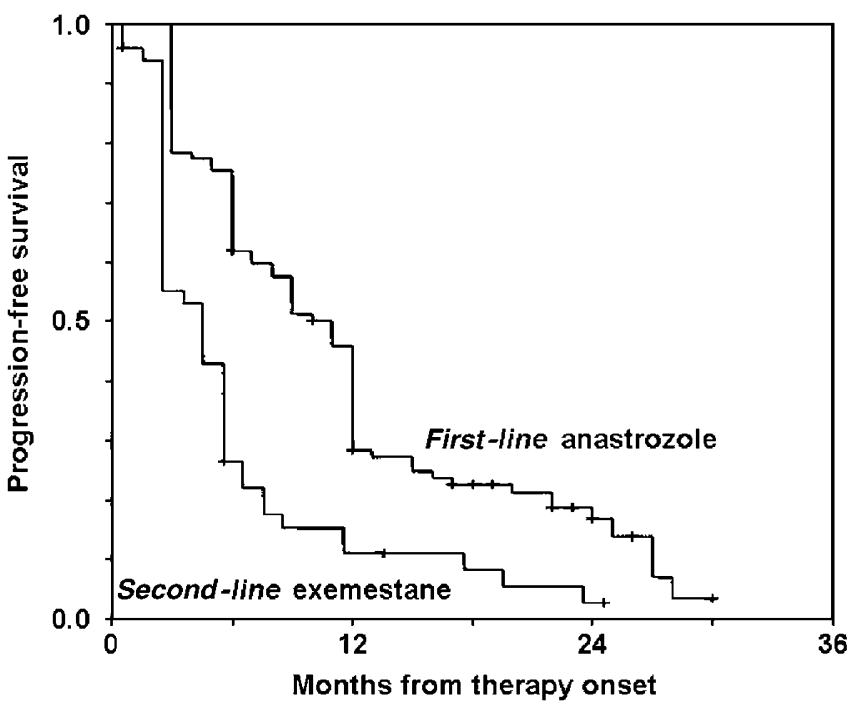

Figure I Progression-free survival. 
In all, 18 additional patients had a long-term disease stabilisation ( $\geqslant 6$ months), providing a clinical benefit rate of $44 \%(95 \%$ CI: $30.0-58.7 \%$ ); seven other patients had a stabilisation lasting 4-6 months. Among the 25 patients who had SD following exemestane therapy, 24 had previously responded to AN; however, the only patient with SD who had previously had a PD following AN had the longest SD duration $(25+$ months).

Altogether, 20 patients had a PD at exemestane evaluation, and one patient was not evaluable for response because of a treatmentlimiting gastro-intestinal pain.

In all, 46 patients discontinued the second-line, exemestane therapy; 45 because of a PD, and one because of gastro-intestinal pain. The median duration of exemestane therapy and follow-up was 5 months (range: $3-25+$ months). The median KaplanMeier, progression-free survival estimate was 5 (95\% CI: 3-7) months (Figure 1).

Also, second-line exemestane was well tolerated. No patient manifested any thrombo-embolic event or bone fracture. Five (10\%) patients had a grade 1-2 osteo-articular pain, $10(20 \%)$ manifested hot flushes and $12(24 \%)$ manifested a grade 1-2 nausea and vomiting. Moderate grade fatigue was reported in $14 \%$ of patients.

\section{DISCUSSION}

Over the last few years, with the widespread availability of letrozole, AN and exemestane, the goal of developing highly effective, well-tolerated, orally active AIs has been realised.

Data from two recent trials that compared AN with megestrol Acetate in second line confirmed that AN was well tolerated, produced response rates similar to megestrol and determined a significant improvement in global survival although it was not associated with the increase in weight produced by megestrol acetate (Buzdar et al, 1996).

Two similar studies with letrozole in patients in relapse with adjuvant tamoxifen or first-line antioestrogens, demonstrated that letrozole can obtain efficiency results similar or superior to megestrol acetate (Dombernowsky et al, 1998; Buzdar et al, 2001).

Exemestane, the most recently introduced AI, obtained a significant improvement in survival compared to megestrol acetate (Kaufmann et al, 2000).

Both AN and letrozole seem to offer greater effectiveness than tamoxifen in the first-line treatment of women in menopause and with positive receptors (Bonneterre et al, 2001; Mouridsen et al, 2001).

Now there is clear evidence in the international scientific community that these third-generation AIs represent credible therapeutic options such that they can be used in first line at the first relapse in post-menopausal women whether or not they have received adjuvant treatment with tamoxifen. The issue of sequential hormonal treatment has been addressed in clinical studies in which AN was given either before tamoxifen or upon progression on tamoxifen (Thürlimann et al, 2000, 2002). Encouraging overall response rates and meaningful clinical benefit were observed in all of these studies.

Exemestane showed activity in patients in progression after prior treatment with nonsteroidal AIs. Good results were observed in terms of OR and clinical benefit in a comprehensive percentage of over 30\% (Lønning et al, 2000). In so much as these data are less favourable than those reported with tamoxifen after AN, it is, in any case, confirmed that there is an interest in using exemestane in third line for patients pretreated both with tamoxifen and with non-steroidal AIs.

The rationale for the sequential use of triazole derivatives, such as $\mathrm{AN}$, and steroidal compounds, such as exemestane, lies in the difference between the two classes of compounds with respect to their biochemical action on the aromatase enzyme. In fact, while nonsteroidal compounds bind to the p450 site of the aromatase complex, the steroidal compounds bind to the substrate-binding pocket.

The results of our work show several interesting aspects. First of all, the toxicity level was especially low; treatment was suspended in only two cases, once in first-line therapy and once in second line, and there were no noteworthy signs of thromboembolism. This allowed sequential treatment to be carried out even for long periods of time with a good quality of life and absolute normalcy of vital functions in almost all patients. If the total of ORs $(\mathrm{CR}+\mathrm{PR})$ is consistent with that described in international literature for firstline treatments, the duration of response and TTP was considerable. Clinical benefit was even more important because of the high percentage of long-lasting SD. This very encouraging result can probably be explained by the high percentage of patients with a known receptorial state and the low percentage of visceral metastases.

Results of second-line responses showed clear evidence of an absence of cross-resistance between the two treatments, which is the consequence of the different mechanism of action. The observed high TTP in second line is also to be noted. There is no doubt that, overall, the data of our study confirm the usefulness of sequential hormonal treatment for patients with adequate clinical indication. A brief reflection should be made on the dropout of about $50 \%$ of the patients in second-line treatment. This is frequently due to a widely shared opinion that chemotherapy could be a better therapeutic option in this setting. This view is very common especially among patients and relatives, and does of course influence medical behaviour.

In conclusion, our study gives clear insights into the feasibility and activity of a sequential hormonal approach in the treatment of selected patients with advanced breast cancer. Future studies with this sequential combination of $\mathrm{AN}$ and exemestane will help to clarify the real allocation in the therapeutic armamentarium against advanced breast cancer. Along with the use of new upcoming hormonal agents, this may represent a valuable approach which can, at least, defer the start of chemotherapy.

\section{REFERENCES}

A'Hern (2001) Stat Med 20: 859-866

Bonneterre J, Buzdar A, Nabholtz JM, Robertson JF, Thürlimann B, von Euler M, Sahmoud T, Webster A, Steinberg M, Arimidex Writing Committee, Investigators Committee Members (2001) Anastrozole is superior to tamoxifen as first-line therapy in hormone receptor positive advanced breast carcinoma. Cancer 92: 2247-2258

Bonneterre J, Thurlimann BJK, Robertson JFR (1999) Preliminary results of a large comparative multi-centre clincal trial comparing the efficacy and tolerability of Arimidex (Anastrozolo) and Tamoxifene (TAM) in postmenopausal women with advanced breast cancer. Eur J Cancer 35(Suppl 4): S313 (abstr. 1257. ECCO 10 Vienna 12-16 September)
Buzdar A, Douma J, Davidson N, Elledge R, Morgan M, Smith R, Porter L, Nabholtz J, Xiang X, Brady C (2001) Phase III, multicenter, double-blind, randomized study of letrozole, an aromatase inhibitor, for advanced breast cancer vs megestrol acetate. J Clin Oncol 19: $3357-3366$

Buzdar A, Jonat W, Howell A, Jones SE, Blomqvist C, Vogel CL, Eiermann W, Wolter JM, Azab M, Webster A, Plourde PV (1996) Anastrozole, a potent and selective aromatase inhibitor, versus megestrol acetate in postmenopausal women with advanced breast cancer: results of overview analysis of two phase III trials. Arimidex Study Group. J Clin Oncol 14: 2000-2011 
Buzdar AU, Hortobagyi G (1998) Update on endocrine therapy for breast cancer. Clin Cancer Res 4: 527-534

Buzdar AU, Jonat W, Howell A, Jones SE, Blomqvist CP, Vogel CL, Eiermann W, Wolter JM, Steinberg M, Webster A, Lee D (1998) Anastrozole versus megestrol acetate in the treatment of postmenopausal women with advanced breast carcinoma: results of a survival update based on a combined analysis of data from two mature phase III trials. Cancer 83(6): 1142 - 1152

Carlson RW (2002) Sequencing of endocrine therapies in breast cancer integration of recent data. Breast Cancer Res Treat 75: S27-S32

Carlson RW, Anderson BO, Bensinger W, Burstein H, Cox CE, Edge SB, Farrar WB, Goldstein LJ, Gradishar WJ, Hudis C, Ljung B-M, Marks L, McCormick B, Nabell LM, Pierce LJ, Reed EC, Silva E, Silver SM, Smith ML, Somlo G, Theirault R, Ward JH, Winer EP, Wolff A (2003) NCCN practice guidelines for breast cancer. JNCCN 1: $148-188$

Carlson RW, Henderson IC (2003) Sequential hormonal therapy for metastatic breast cancer after adjuvant tamoxifen or anastrozole. Breast Cancer Res Treat 80(Suppl 1): S19-S26

CTC Version 2.0. Cancer Therapy Evaluation Program. Common Toxicity Criteria, Version 2.0. DCTD, NCI, NIH, DHHS. March 1998. Publish Date: April 1999

di Salle E, Ornati G, Paridaens R (1994) Preclinical and clinical pharmacology of the aromatase inhibitor exemestane (FCE 24304). In Sex Hormone and Antihormones in Endocrine Dependent Pathology: Basic and Clinical Aspects Motta M, Serio E (eds) pp 303-310. Amsterdam, The Netherlands: Elsevier Science B.V.

Dombernowsky P, Smith I, Falkson G, Leonard R, Panasci L, Bellmunt J, Bezwoda W, Gardin G, Gudgeon A, Morgan M, Fornasiero A, Hoffmann W, Michel J, Hatschek T, Tjabbes T, Chaudri HA, Hornberger U, Trunet PF (1998) Letrozole, a new oral aromatase inhibitor for advanced breast cancer: double-blind randomized trial showing a dose effect and improved efficacy and tolerability compared with megestrol acetate. J Clin Oncol 16: $453-461$

Fleming (1982) Biometrics 38: $143-151$

Hortobagyi GN (1998a) Drug therapy: treatment of metastatic breast cancer. $N$ Engl J Med 339: $974-984$

Hortobagyi GN (1998b) Progress in endocrine therapy for breast carcinoma. Cancer 83: 1-6

Johannessen DC, Engan T, Di Salle E, Zurlo MG, Paolini J, Ornati G, Piscitelli G, Kvinnsland S, Lonning PE (1997) Endocrine and clinical effects of exemestane (PNU 155971), a novel steroidal aromatase inhibitor, in postmenopausal breast cancer patients: a phase I study. Clin Cancer Res 3(7): 1101-1108

Jones S, Belt R, Cooper B (1998) A phase II study of antitumor efficacy and safety of exemestane (EXE) as second-line hormonal treatment of postmenopausal patients with metastatic breast cancer (MBC) refractory to tamoxifen (Tam). Breast Cancer Res Treat 50: 304 (abstr 436)
Kaufmann M, Bajetta E, Dirix LY, Fein LE, Jones SE, Zilembo N, Dugardyn JL, Nasurdi C, Mennel RG, Cervek J, Fowst C, Polli A, di Salle E, Arkhipov A, Piscitelli G, Miller LL, Massimini G (2000) Exemestane is superior to megestrol acetate after tamoxifen failure in postmenopausal women with advanced breast cancer: results of a phase III randomised double-blind trial. The Exemestane Study Group. J Clin Oncol 18: $1399-1411$

Kvinnsland S, Anker G, Dirix LY (1998) Activity of exemestane, an irreversible, oral, aromatase inhibitor in metastatic postmenopausal breast cancer patients (MBC) failing tamoxifen (TAM). Eur J Cancer 34: S91 (suppl 5, abstr 408)

Lønning PE, Bajetta E, Murray R, Tubiana-Hulin M, Eisenberg PD, Mickiewicz E, Celio L, Pitt P, Mita M, Aaronson NK, Fowst C, Arkhipov A, di Salle E, Polli A, Massimini G (2000) Activity of exemestane in metastatic breast cancer after failure of nonsteroidal aromatase inhibitors: a phase II trial. J Clin Oncol 18: 2234-2244

Mouridsen H, Gershanovich M, Sun Y, Perez-Carrion R, Boni C, Monnier A, Apffelstaedt J, Smith R, Sleeboom HP, Janicke F, Pluzanska A, Dank M, Becquart D, Bapsy PP, Salminen E, Snyder R, Lassus M, Verbeek JA, Staffler B, Chaudri-Ross HA, Dugan M (2001) Superior efficacy of letrozole versus tamoxifen as first-line therapy for postmenopausal women with advanced breast cancer: results of a phase III study of the International Letrozole Breast Cancer Group. J Clin Oncol 19: 2596-2606

Nabholtz JM, Bonneterre J, Buzdar A, Robertson JF, Thurlimann B (2003) Anastrozole (Arimidex) vs tamoxifen as first-line therapy for advanced breast cancer in postmenopausal women: survival analysis and updated safety results. Eur J Cancer 39(12): 1684-1689

Nabholtz JM, Buzdar A, Pollak M, Harwin W, Burton G, Mangalik A, Steinberg M, Webster A, von Euler M (2000) Anastrozole is superior to tamoxifen as first-line therapy for advanced breast cancer in postmenopausal women: results of a North American multicenter randomized trial. Arimidex Study Group. J Clin Oncol 18(22): 3758-3767

Robertson JF, Howell A, Buzdar A, von Euler M, Lee D (1999) Static disease on anastrozole provides similar benefit as objective response in patients with advanced breast cancer. Breast Cancer Res Treat 58(2): 157-162

Taylor IV SG, Gelman RS, Falkson G (1986) Combination chemotherapy compared to tamoxifen as initial therapy for stage IV breast cancer in elderly women. Ann Intern Med 104: 455-461

Thürlimann B, Hess D, Koeberle D, Senn I, Ballabeni P, Pagani O, Perey L, Aebi S, Rochlitz C, Goldhirsch A (2002) Anastrozole ('Arimidex') vs tamoxifen as first-line therapy in postmenopausal women with advanced breast cancer: results of the double-blind crossover SAKK trial 21/95 - a sub-study of anastrozole trial 0027. Breast Cancer Res Treat 76(Suppl 1): S73 (abstr 255)

Thürlimann B, Robertson JFR, Bonneterre J (2000) Efficacy of tamoxifen following Arimidex (anastrozole) as first-line treatment for advanced breast cancer (ABC) in postmenopausal women (PM). Breast Cancer Res Treat 64(Suppl): S51 